\title{
Phosphatidylglycerol to Lung Surfactant Ratio Measurement
}

National Cancer Institute

\section{Source}

National Cancer Institute. Phosphatidylglycerol to Lung Surfactant Ratio Measurement. NCI Thesaurus. Code C147423.

The determination of the ratio of phosphatidylglycerol compared to lung surfactant present in a sample. The measurement may be expressed as a ratio or percentage. 